\title{
Physical and Psychological Effects of the Shiatsu Stimulation in the Sitting Position
}

\author{
Shinpei Oki1,2, Koichi Ouchi ${ }^{1,3,4}$, Mayumi Watanabe ${ }^{5,6^{*}}$, Nozomu Mandai6 \\ ${ }^{1}$ Oriental Medical Care Teacher Training, Tokyo Professional School of Medical and Welfare, Tokyo, Japan \\ ${ }^{2}$ Japan Shiatsu College, Tokyo, Japan \\ ${ }^{3}$ Rehabilitation Sciences, University of Tokyo Health Sciences, Tokyo, Japan \\ ${ }^{4}$ Medical Informatics, Niigata University, Niigata, Japan \\ ${ }^{5}$ Chuo University, Tokyo, Japan \\ ${ }^{6}$ Ibaraki Prefectural University of Health Sciences, Ibaraki, Japan \\ Email: *watanabem62@gmail.com
}

How to cite this paper: Oki, S., Ouchi, K., Watanabe, M. and Mandai, N. (2017) Physical and Psychological Effects of the Shiatsu Stimulation in the Sitting Position. Health, 9, 1264-1272.

https://doi.org/10.4236/health.2017.98091

Received: April 13, 2017

Accepted: August 27, 2017

Published: August 30, 2017

Copyright $\odot 2017$ by authors and Scientific Research Publishing Inc. This work is licensed under the Creative Commons Attribution International License (CC BY 4.0).

http://creativecommons.org/licenses/by/4.0/

\begin{abstract}
Purpose: In this study, we investigated physical and psychological effects of the shiatsu (finger pressure) stimulation in a sitting position. Subjects and Methods: A crossover test was conducted on 20 subjects (average $34.5 \pm 7.6$ years old; male $=10$, female $=10$ ). First they were randomly divided into two groups: Group A (shiatsu stimulation/control) and group B (control/shiatsu stimulation). They had shiatsu stimulation (Namikoshi basic methods in the sitting position, five minutes). At the same time, POMS (profile of mood states), SBP (systolic blood pressure, DBP (diastolic blood pressure) and HR (heart rate) were measured. Results: Physical result-Compared to the baseline, the shiatsu stimulation showed statistical decreased SBP and HR while the control (no shiatsu stimulation) did not. Psychological result (POMS) Compared to the baseline, the stimulation showed significant change in all six mood states (Tension-Anxiety, Depression-Dejection, Fatigue and Confusion decreased while Vigor elevated). Male showed statistical decrease in Tension-Anxiety, Depression-Dejection, Anger, Fatigue and Confusion as well as significant increase in Vigor. Female only showed decrease in Depression-Dejection and Anger. Discussion and Conclusion: The shiatsu stimulation in the sitting position could modulate autonomic nerve system and it could affect human body. Gender differences were found in physiological effect.
\end{abstract}

\section{Keywords}

Shiatsu Stimulation, POMS, Blood Pressure, Heart Rate 


\section{Introduction}

Shiatsu therapy, finger pressure stimulation, is the application of manual pressure to the skin. Its origin can be found in traditional Chinese/Japanese medicine and it was established by Tokujiro Namikoshi in the first half of last century [1]. Its technique refers to the use of fingers and the palm of one's hands to apply pressure to particular sections on the surface of the body for the purpose of health promotion [2].

There are many evidences on medicine of acupuncture therapy as well as acupuncture-like stimulations. The former is inserted subcutaneously while the latter just give soft pressure on a very small area of the skin (diameter $5.0 \mathrm{~mm}$ ) [3] [4]. Moreover, shiatsu stimulation, which presses more area (finger diameter), might also be considered effective, though it has not been investigated. Unlike massage or acupuncture, shiatsu stimulation can be given without undressing. In short, shiatsu stimulation is a simple and convenient therapy.

Researchers reported that shiatsu stimulation worked for sleep disorders [5], painless delivery [6] nausea, vomiting of pregnancy [7]. However, there is room or further research because there have been few scientific studies conducted to shed light on effects of shiatsu stimulation. Therefore, we studied physical and psychological effects of shiatsu (finger pressure) stimulation in a sitting position in this study.

\section{Methods}

\subsection{Subjects}

Participants were 20 physically and mentally healthy students. Our subjects were elder than or equal to 20 years old without diseases. Their profile is shown in Table 1. This experiment was conducted using a cross over design. They received two kinds of interventions; one was shiatsu stimulation and the other one was control (without shiatsu stimulation) on different days (Figure 1). Subjects were randomly divided into two groups Group A and Group B ( $n=10,5$ male and 5 female, respectively). Group A received shiatsu intervention in the first experiment session and then received no shiatsu intervention in the second session. Group B completed sessions in a reverse sequence. The second experiment was conducted more than one week after the first experiment.

All participants were informed of the purpose and nature of the experiments; then a written consent was obtained from each participant, in compliance with the World Medical Association Declaration of Helsinki. Written informed consent

Table 1. Profile of participants.

\begin{tabular}{cccc}
\hline Subjects (n) & Male (10) & Female (10) & Total (20) \\
\hline Number (\%) & $10(50.0)$ & $10(50.0)$ & $20(100.0)$ \\
Age & $33.4 \pm 7.0$ & $35.6 \pm 8.7$ & $34.5 \pm 7.6$ \\
Marriage \pm & $3 / 7$ & $5 / 5$ & $8 / 12$ \\
\hline
\end{tabular}


timulation

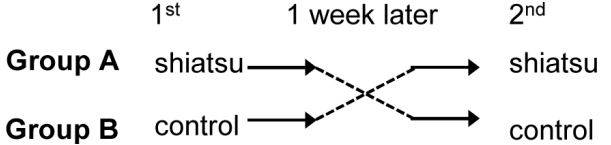

One group received shiatsu stimulation in the first experiment session and then received no shiatsu stimulation in the second session (Group A). The other group completed sessions in a reverse sequence (Group B).

Figure 1. Experimental design.

(a)

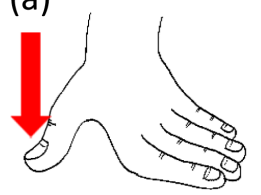

(d)

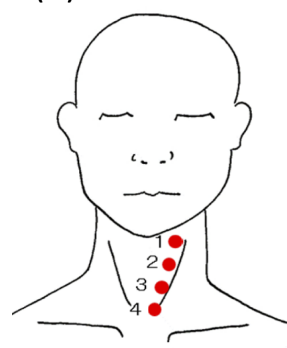

(g)

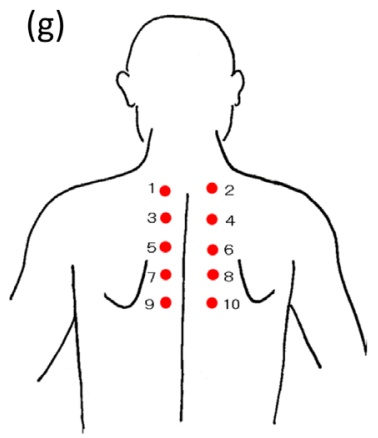

(b)

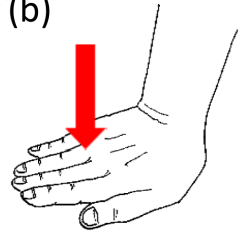

(e)

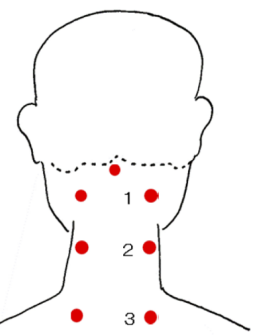

(c)

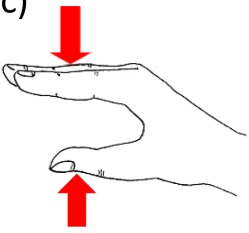

(f)

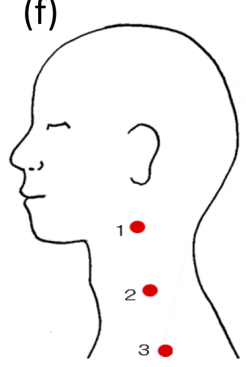

(h)

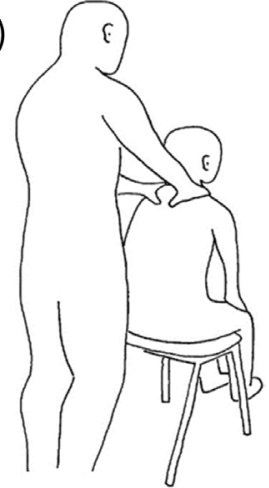

(1) internally press sternocleidomastoid with (a) as shown in (d), (2) press from the lower edge of mastoid part of the temporal bone to C6 with (c) (three times), (3) press the hollow of the nape with (a) (three times), (4) press three points (from the middle of mastoid and 3) to the C7 level) with (c) (three times) (f), (5) press the center of temporal region with (b), (6) press both shoulders with (a) at the same time (three times), (7) press five points with (a) (from Th 1 level to Th 7 level) (g) (h), (8) stroke shoulders with (b) (two times) and then, (9) stroke the spinal column with (b) (two times).

Figure 2. Shiatu stimulation (Namikoshi basic methods in the sitting position, five minutes). Three techniques of shiatsu pressure and points/cites of shiatsu stimulation.

was obtained from all subjects and the study was approved by the institutional review board of Tokyo Professional School of Medical and Welfare (Tokyo, Japan).

\subsection{Shiatsu Stimulation}

The shiatsu stimulation (Namikoshi basic methods of shiatsu in the sitting position, five minutes) was conducted as below (Figure 2).

The experiments were conducted in a room with the temperature set at $24.4^{\circ} \mathrm{C}$ 
$\pm 1.1^{\circ} \mathrm{C}$ and $57.7 \% \pm 12.1 \%$ humidity throughout the experimental sessions.

\subsection{Physiological Effect-Blood Pressure and Heart Rate}

Blood pressure and heart rate were measured at the same time with an arm-cuff blood pressure monitor (HEM-7132, OMRON Corporation, Kyoto, Japan).

\subsection{Profile of Mood States (Japanese Version)}

To investigate mood states, participants also completed the Profile of Mood States (POMS) [8], a self-rated scale measuring six mood states [T-A (tension-anxiety), $\mathrm{D}$ (depression-dejection), A-H (anger-hostility), V (vigor), F (fatigue), and C (confusion)] and total mood disturbance, which is a summary score for the emotional state subscales. The POMS is a widely used, reliable measure of emotional distress [9] [10]. Research shows that the POMS is reliable for Japanese participants [11] [12]; therefore, in this study, we used the Japanese version of the POMS [13] as we studied in advance [14].

\subsection{Statistical Analysis}

The Wilcoxon signed rank test and Mann-Whitney $U$ test were conducted and the level of significance was set at $\mathrm{p}<0.05$. The values presented ere expressed as range as well as mean \pm SD. All statistical analyses were performed using SPSS Statistics for Windows version 20.0 (IBM Corp, Armonk, NY).

\section{Results}

\subsection{Physiological Effects-Blood Pressure and Heart Rate}

Compared to the baseline, the shiatsu stimulation showed statistical decreased SBP and HR ( $\mathrm{p}<0.01)$ while the control (no shiatsu stimulation) did not

And then they were divided into two groups by gender, however, no statistical difference were obtained in each group (Figure 3 ).

\subsection{Psychological Effects-POMS}

Compared to the baseline shiatsu stimulation showed significant change in all six mood states (T-A, D, A-H, F and C, p < 0.01; V, p < 0.05). At that time, the control (without shiatsu stimulation) did not indicate such chances except in the A-H $(\mathrm{p}<0.01)$ (Figure 4).

Next gender differences were examined. Male (blue color) showed the same changes as above mentioned (T-A, D, V, F and C; $\mathrm{p}<0.01$; A-H, p < 0.05). At that time, female (red color) indicated nominal decrease in only in two areas of $\mathrm{D}$ and $\mathrm{A}-\mathrm{H}(\mathrm{p}<0.01)$. Thus, gender differences were observed in psychological effect (POMS).

\section{Discussion}

\subsection{Physiological Effects-Blood Pressure and Heart Rate}

Our result indicated that the shiatsu stimulation decreased SBP and HR. Our 
result indicated that the shiatsu stimulation decreased SBP and HR.

First, we may find one reason in the baroceptor reflex (via glossopharyngeal nerve IX-solitary nucleus in the medulla-vagal nerve $\mathrm{X}$ ). It provides a rapid negative feedback to hypertension and modulates blood pressure and heart rate induced by excessive sympathetic nerve dominance [15] [16] [17]. The carotid sinus is the reflex center. Our shiatsu stimulation on the inside of sternocleidomastoid muscle could also affect carotid sinus in the internal carotid artery because they are located near each other.

\subsection{Psychological Effects-POMS}

Our result indicated that the shiatsu stimulation influenced on POMS, a psychological test. After the shiatsu stimulation the results of all and male showed that negative mood states (T-A, D, A-H, F and C) while the positive state (V) increase. The former states were mainly controlled by sympathetic nervous system $(\mathrm{SN})$ while the latter state was largely influenced by parasympathetic nerve system (PN).

The interest was that the control group nominally showed decrease in the negative mood state of A-H. Nowadays half of Japanese people suffer from stress [18]. Subjects in control group might also have stress though they took 5 minutes rest before the experiment. And then, when subjects in shiatsu group had stimulation of 5 minutes, control subjects could enjoy more 5 minutes as rest time. In this way, A-H mood state showed decrease both in both groups. Needless to say, our result showed that more than 5 minutes rest time is needed before experiments.

all

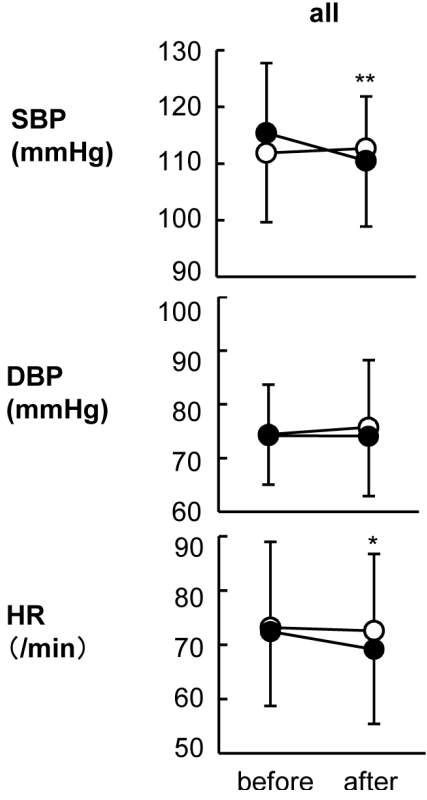

female
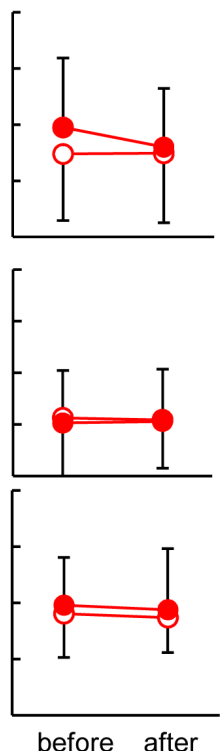

male
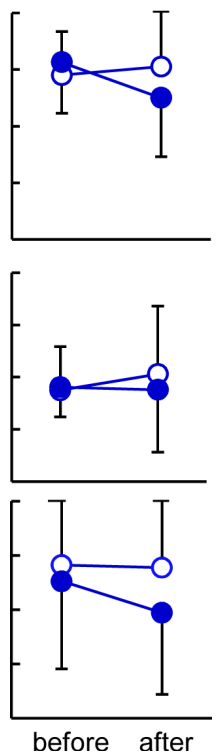

The shiatsu group showed statistical decreased SBP (systolic blood pressure) and HR (heart rate) after the shiatsu stimulation ( $\mathrm{p}<0.01$ ) while the other group did not. DBP (diastolic blood pressure) did not show such difference. $\mathrm{O}$ : control, $\mathrm{O}$ : shiatsu stimulation, data are mean $\pm \mathrm{SEM} .{ }^{*} \mathrm{p}<0.05$, ${ }^{* *} \mathrm{p}<0.01$.

Figure 3. Physiological effects-blood pressure and heart rate. 


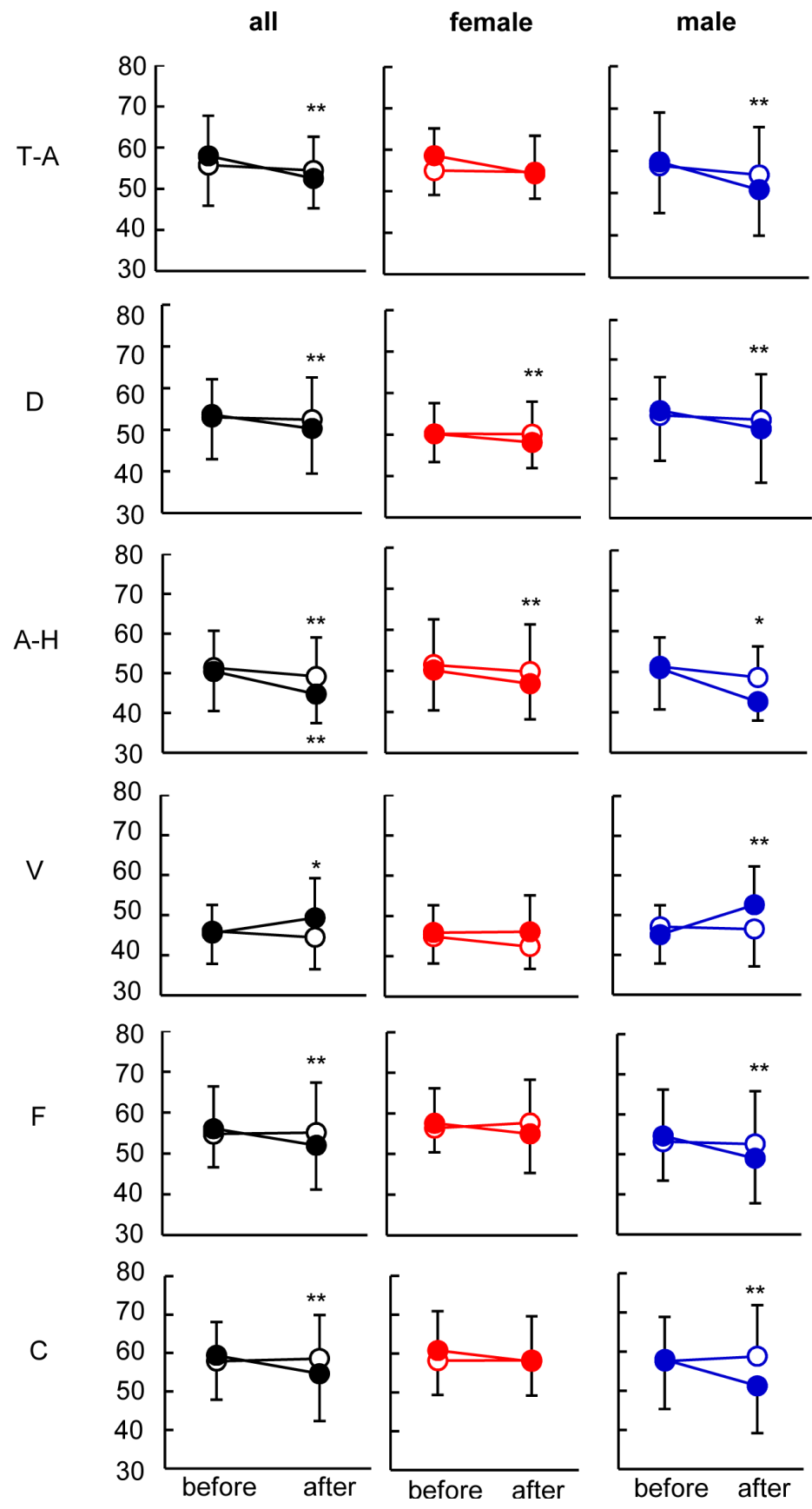

The shiatsu group showed significant change in all six mood states [T-A (tension-anxiety), D (depression-dejection), A-H (anger-hostility), V (vigor), F (fatigue), and C (confusion)]. (T-A, D, A-H, $\mathrm{F}$ and $\mathrm{C}, \mathrm{p}<0.01 ; \mathrm{V}, \mathrm{p}<0.05)$. At that time, the control group did not indicate such chances except in the A-H. Male (blue color) showed statistic changes (T-A, D, V, F and C; $\mathrm{p}<0.01 ; \mathrm{A}-\mathrm{H}, \mathrm{p}<0.05$ ). Female (red color) indicated nominal decrease only in D and A-H $(\mathrm{p}<0.01)$. O: control, $\mathbf{0}$ : shiatsu stimulation, data are mean \pm SEM. ${ }^{*} \mathrm{p}<0.05,{ }^{* *} \mathrm{p}<0.01$.

Figure 4. Psychological effects-POMS (the Profile of Mood States).

\subsection{Gender Difference}

Our results also indicated gender differences because female indicated differences only in D and A-H. As those negative mood states were possibly caused by sympathetic nerve dominance which was induced by stress [19]. It is widely 
known that stress, affect various hormones, such as adrenaline, cortisol, dopamine and so on [20] [21] [22]. Moreover, gender differences are found in those hormones and the number and subsets of leucocytes and male are basically more SN dominance [23]. As for gender difference in psychological field, Shichiri K reported in detail [14] [24].

In this way, the effects of shiatsu stimulation have gender differences on subject. In further study, we have to also discuss on gender difference of therapists.

Thus, our results showed that the shiatsu stimulation in the sitting position for five minutes indicated both physiological and psychological effects.

However, there are limitations. Our application was given in the sitting position. Nishijyo reported, different in efficiencies were observed in the different positions [25]. Therefore, we have to discuss shiatsu stimulation in other positions in larger scale with wider range of age as well as repetitive stimulation after an appropriate time points (e.g. days, weeks) to see if individual subjects respond similarly.

\section{Conclusion}

The shiatsu stimulation indicated both physiological and psychological effects. The pathway of those effects might be induced by decreasing SN/increasing PN. Gender differences were found in physiological effect.

\section{Acknowledgements}

The authors thank all of the subjects who participated in this study.

\section{References}

[1] Canadian Shiatsu Society of British Colombia (2017) The Complete Book of Shiatsu Therapy. http://www.shiatsupractor.org http://www.shiatsupractor.org/?page_id=15

[2] Textbook Writing Subcommittee (1985) Anma Massage Shiatsu Theory. Ido No Nippon Sha, Tokyo.

[3] Watanabe, M., Takano, O., Tomiyama, C., Matsumoto, H., Urahigashi, N., Kainuma, E., Madarame, T., Fukuda, M. and Abo, T. (2012) The Effects of Application of an Ancient Type of Acupuncture Needle on Body Temperature, Immune Function and the Autonomic Nerve System. Health, 4, 775-780.

https://doi.org/10.4236/health.2012.410120

[4] Watanabe, M., Takano, O., Tomiyama, C., Guan, J., Hou, G., Mori, H., Nishijo, N. and Abo, T. (2013) The Effects of Application of an Ancient Type of Acupuncture Needle on Increase in Urination of Hospitalized Oldest-Old People. Health, 5, 1092-1098. https://doi.org/10.4236/health.2013.57147

[5] Ohata, N. and Kaibara, Y. (1999) The Effect of the Acupressure on a Sleepless Patient. Japanese Nursing Society Memoir. Adult Nursing, 30, 170-172.

[6] Utsuki, T. (1962) Pressure Method of Delivery of Painless and Relief of Pain. Acta Obstetrica et Gynaecologica Japonica, 17, 910-911.

[7] Belluomini, J., Litt, R.C., Lee, K.A. and Katz. M. (1994) Acupressure for Nausea and Vomiting of Pregnancy: A Randomized, Blinded Study. Obstetrics and Gynecology, 84, 245-248. 
[8] McNair, D., Lorr, A. and Droppleman, L. (1971) EITS Manual for the Profile of Mood States. Educational and Industrial Testing Service, San Diego.

[9] McCorkle, R. and Quint-Benoliel, J. (1983) Symptom Distress, Current Concerns and Mood Disturbance after Diagnosis of Life-Threatening Disease. Social Science \& Medicine, 17, 431-438. http://dx.doi.org/10.1016/0277-9536(83)90348-9 http://www.ncbi.nlm.nih.gov/pubmed/?term=McCorkle+R\%2C+Quint-Benoliel+J

[10] Silberfarb, P.M., Holland, J.C.B., Anbar, D., Balma, G., Maurer, H., Chahinian, A.P. and Comis, R. (1983) Psychological Response of Patients Receiving Two Drug Regimens for Lung Carcinoma. American Journal of Psychiatry, 140, 110-111. http://dx.doi.org/10.1176/ajp.140.1.110

[11] Akechi, T., Fukue-Saeki, M., Kugaya, A. and Okamura, H. (2000) Psychometric Properties of the Japanese Version of the Mental Adjustment to Cancer (MAC) Scale. Psycho-Oncology, 9, 395-401.

http://www.ncbi.nlm.nih.gov/pubmed/11038477 http://dx.doi.org/10.1002/1099-1611(200009/10)9:5<395::AID-PON472>3.0.CO;2-O

[12] Yokoyama, K., Araki, S., Kawakami, N. and Takeshita, T. (1990) Production of Japanese Edition of Profile of Mood States (POMS): Assessment of Reliability and Validity. Japanese Journal of Public Health, 37, 913-918.

[13] Yokoyama, K. and Araki, S. (2000) Companion to POMS. 3rd Edition, Kaneko Shobo Ltd., Tokyo.

[14] Shichiri, K., Shibuya, M., Watanabe, M., Tahashi, M., Kaminushi, K., Uenoyama, T., Mashim, I., Murayama, K., Kuroda, T. and Suzuki, Y. (2016) Correlations between the Profile of Mood States (POMS) and the WHOQOL Japanese University Students. Health, 8, 416-420. https://doi.org/10.4236/health.2016.85044

[15] Sadayasu, T., Nakamura, T., Kouzuma, R., Takahara, K. and Nakashima, Y. (1999) Autonomic Nerve Function Expressed by the Baroreflex Sensitivity (BRS) in Elderly Adults. Japanese Journal of Geriatrics, 36, 793-798. https://doi.org/10.3143/geriatrics.36.793

[16] Delaney, J.P., Leong, K.S., Watkins, A. and Brodie, D. (2002) The Short-Term Effects of Myofascial Trigger Point Massage Therapy on Cardiac Autonomic Tone in Healthy Subjects. Journal of Advanced Nursing, 37, 364-371. https://doi.org/10.1046/j.1365-2648.2002.02103.x

[17] Kubokawa, T., Maruyama, H. and Kurosawa, M. (1997) Blood Pressure Change and the Mechanism in a Rat under the Opiate by an Abdominal Stimulus Like Massaging. Rigaku Ryohogaku, 24, 382.

[18] Japan Cabinet Office (2003) White Paper on the National Lifestyle H20. http://www5.cao.go.jp/seikatsu/whitepaper/h20/10_pdf/01_honpen/

[19] Abo, T., Kawamura, T., Tomiyama-Miyaji, C. and Watanabe, M. (2010) Autonomic Nervous System Control of Leukocyte Distribution: Physiology and Implications for Common Human Diseases.

http://brainimmune.com/autonomic-nervous-system-control-of-leukocyte-distribu tion-physiology-and-implications-for-common-human-diseases/

[20] Kainuma, E., Watanabe, M., Tomiyama-Miyaji, C., Inoue, M., Kuwano, Y., Ren, H. and Abo, T. (2009) Association of Glucocorticoid with Stress-Induced Modulation of Body Temperature, Blood Glucose and Innate Immunity. Psychoneuroendocrinology, 34, 1459-1468. https://doi.org/10.1016/j.psyneuen.2009.04.021

[21] Watanabe, M., Tomiyama-Miyaji, C., Kainuma, E., Inoue, M., Kuwano, Y., Ren, H., Shen, J. and Abo, T. (2008) Role of Alpha-Adrenergic Stimulus in Stress-Induced Modulation of Body Temperature, Blood Glucose and Innate Immunity. Immunology Letters, 115, 43-49. https://doi.org/10.1016/j.imlet.2007.09.010 
[22] Maruyama, K., Shimoju, R., Ohkubo, M., Maruyama, H. and Kurosawa, M. (2012) Tactile Skin Stimulation Increases Dopamine Release in the Nucleus Accumbens in Rats. Journal of Physiological Sciences, 62, 259-266. https://doi.org/10.1007/s12576-012-0205-Z

[23] Abo, T., Fukuda, M., Honda, S., Sato, Y., Toma, H., Suzuki, S. and Sekikawa H. (1997) Environmental Factors Affecting the Life Span of Men and Women. Biomedical Research, 18, 265-271. https://doi.org/10.2220/biomedres.18.265

[24] Shichiri, K., Shibuya, M., Murayama, K., Sato, C., Kaminushi, K., Uenoyama, T., Mashima, I., Kuroda, T. and Suzuki, Y. (2015) Features of Developmental Level of Defense Mechanisms and Adjustment Status of University Students in Japan. Health, 7, 52-57. https://doi.org/10.4236/health.2015.71007

[25] Nishijyo, K. (2013) The Scientific Clinical Acupuncture-A Signpost for Scientific Approach of Clinical Acupuncture. 2nd Edition, Ishiyau Pubishiers Inc., Tokyo.

Submit or recommend next manuscript to SCIRP and we will provide best service for you:

Accepting pre-submission inquiries through Email, Facebook, LinkedIn, Twitter, etc. A wide selection of journals (inclusive of 9 subjects, more than 200 journals)

Providing 24-hour high-quality service

User-friendly online submission system

Fair and swift peer-review system

Efficient typesetting and proofreading procedure

Display of the result of downloads and visits, as well as the number of cited articles

Maximum dissemination of your research work

Submit your manuscript at: http://papersubmission.scirp.org/

Or contact health@scirp.org 